\title{
Demanslı Yaşılıara Uygulanan Sanat Terapi Yönteminin Bilişsel Durum Üzerine Etkisinin İncelenmesi
}

\section{Investigation of the Impact of Art Therapy Methodology Applied to the Elderly Individuals with Dementia on Cognitive State}

\author{
Serap Bulduk ${ }^{1}$, Yeliz Dinçer ${ }^{1}$, Esra Usta ${ }^{1}$, Sevgi Bayram ${ }^{2}$ \\ 1 Düzce Üniversitesi Sağlık Hizmetleri Meslek Yüksek Okulu, Yaşlı Bakımı Programı \\ 2 Düzce Üniversitesi Gölyaka Meslek Yüksek Okulu, Grafik Tasarım Bölümü
}

öz

Amaç: Demans küresel olarak önemli sağlık problemlerinden biridir. Demansta tedavi seçeneklerinin ve etkinliğinin sınırl olması, farmakolojik olmayan müdahaleler ile yaşam kalitesinin artırılması konusundaki çalışmaları yönlendirmiştir. Bunlardan biri olan sanat terapisinin demanslı yaşlıların duygu durum ve bilişsel özellikleri üzerinde ki etkileri çeşitli çalışmaların kapsamında incelenmiştir. Bu doğrultuda bu çalışma yaşlılara yönelik yürütülecek olan sanat terapi yönteminin hafif demansı olan yaşlıların bilişsel durumu üzerine etkisini incelemek amacı ile yarı-deneysel olarak hafif demansı olan 16 yaşı birey yürütülmüştür.

Gereç ve Yöntem: Çalıșmanın verileri, araştırmacılar tarafından hazırlanan "Bireysel Bilgi Formu" ve "Standardize Mini Mental Test" (MMT) kullanılarak toplanmıştır. Çalışmada, bu sanat eğitimi almış olan bir araştırmacı tarafından resim, heykel, nesne-canlı resmi boyama, kolaj vb. teknikler kullanılarak "Sanat Terapisi" uygulanmıştır.

Bulgular ve Sonuç: Katılımcıların yaş ortalaması $73,0 \pm 7.70$ 'dır. Yaşlıların sanat terapisi etkinliği öncesi MMT puan ortalaması yaklaşık 21 puan, etkinlikten üç ay sonrası ise 20 puandır. Bu puanlar MMT için hafif demans referans aralığındadır ve etkinlik sonrasında anlamlı bir değişim olmamıştır. Yaşlıların üç ay sonraki MMT puanlarının değişmemiş olması hastalığın ilerleyici özelliği göz önünde bulundurularak makul bir sonuç olarak değerlendirilmiştir. Sanat terapisi demanslı yaşlı bireylerle küçük gruplar halinde düzenli olarak sürdürüldüğünde onların sosyalleşmeleri adına önemli bir kazançtır.

Anahtar Kelimeler: Demans, Sanat Terapisi, Bilişsel

\section{ABSTRACT}

Purpose: Dementia is one of the most important health problems on a global scale. The fact that the treatment options and their effectiveness led to studies about enhancing the quality of life through non-pharmacological interventions. The impacts of the art therapy, one of such interventions, on the mood and cognitive features of the elderly with dementia has been investigated within the scope of various studies. In line with this, this study was conducted on 16 elderly individuals with slight dementia in order to investigate the impact of art therapy technique that is applied to the elderly on the cognitive state of elderly individuals with slight dementia as a quasi-experimental study.

Material and method: The data of the study was collected through "Individual Information Form", which was prepared by the researchers and the "Standardized Mini-Mental Test" (SMMT). During the study, "Art Therapy" was implemented by a researcher who received education on art using such techniques as painting, sculpture, painting objects-living things, collage, etc.

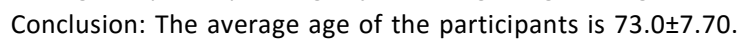
The mean score of the elderly from the SMMT before art therapy implementation is 21 , while this figure is 20 three months after the implementation. These scores are in the reference interval of slight dementia For the SMMT and no significant change was observed following the implementation. Considering the progressive feature of the disease, the fact that the SMMT scores of the elderly did not regularly in small groups of elderly individuals with dementia, it becomes a significant acquisition for their socialization.

Keywords: Dementia, Art Therapy, Cognitive Competence

Corresponding Author: Esra USTA

Address: Düzce Üniversitesi Sağlık Hizmetleri Meslek Yüksek Okulu, Yaşı

Bakımı Programı Düzce- Türkiye 


\section{GíRiş}

Küresel olarak 36 milyon kişiyi etkileyen demans, önemli sağlık problemlerinden biridir. Demansın global prevelansının 2030 yılında 66 milyon ile iki katına, 2050 yılında 115 milyon ile üç katına çıkması beklenmektedir (1). Demanslı kişiler ve bakım vericilerinin yaşadığı en üzücü klinik özellikler nöropsikiyatrik semptomlardır. Apati, depresyon, sanrılar, halüsinasyonlar, saldırganlık, psikomotor ajitasyon, uygunsuz cinsel davranışlar ve uyku kalitesinin düşüklüğü yaygın olarak görülmekte ve zamanla da artma eğilimi göstermektedir $(2,3)$. Bu hızlı bilişsel düşüş, günlük yaşam aktivitelerini olumsuz etkilemekte, yaşam kalitesini düşürmekte, hastanede kalış süresini uzatmaktadır $(3,4)$. Diğer taraftan, demansta tedavi seçeneklerinin ve etkinliğinin sınırlı olduğu gösterilmektedir. Demansta farmakolojik olmayan birçok müdahalenin yaşam kalitesini arttırdığına yönelik kanıtlar vardır. Bu kanıtlar içinde sanat terapisinin yararlı olabildiğine yönelik kanıtlarda bulunmaktadır (5).

Sanat terapisi, sanat materyallerinin kullanıldığı dışavurumcu bir terapi biçimi olarak belirtilmektedir. Yaratıcı sürecin psikolojik yönünü özellikle farklı sanat materyallerinin duygusal özelliklerini anlama ile geleneksel psikoterapötik teori ve tekniklerin birleşiminden oluşmaktadır. Sanat terapisinin tıbbi amaçlı kullanılması ile kişilerde çeşitli zihinsel tasvirlerin yeniden hatırlanması ve dışa vurumunun sağlanması amaçlanmaktadır $(3,4,6,7)$.

Sanat terapisi günlük bakım/yatılı bakım ortamındaki yaşlıların duygu durum ve bilişsel özellikleri üzerinde olumlu etkilere sahiptir. Bir klinik veya bakım ortamında demanslı hastalar ile sanat terapisi genellikle küçük gruplar ile sanat terapisti, sanatçılar ya da kolaylaştırıcı kişiler tarafından yürütülebilir. Demansı hastalarla yürütülen sanat terapisi, hafıza kaybı olan bireylerin durumlarına ilişkin psikolojik ve manevi sorunlarını çözmelerini, düşünmelerini, kişilik ve öz-değer duygularının bazı bölümlerini geri kazanmalarını sağlayabilmektedir (4). Sanat terapisinin sonuçları çeşitli çalışmalarda kalitatif veya kantitatif olarak değerlendirilmiştir. Gözlemler sanat terapisinin dikkati $(8,9)$, benlik saygısını, fiziksel yeterliliği, zihinsel keskinliği, sosyalliği (8), dinginliği (9), iletişimi $(8,10,11)$ ve olumlu duygu durumunu artırdığını $(9,10,12)$; anksiyete (12) ajitasyon, depresyonu ve stresle ilişki davranışları (13) zalttığını göstermiştir. Türkiye'de yaşlılara yönelik yürütülen sanat terapisinin etkinliğinin değerlendirildiği araştırmalar oldukça azdır. Özdemir ve Akdemir (14) çalışmalarında çoklu duyusal uyaran yönteminin bilişsel durum üzerine etkisini MMT (Mini Mental Test) ile değerlendirmiş ve olumlu yönde anlamlı olduğu saptamıştır. Bu çalışma yaşlılara yönelik yürütülecek olan sanat terapi yönteminin hafif demansı olan yaşlıların bilişsel durumu üzerine etkisini incelemek amacı ile yarı-deneysel olarak planlanmıştır.

\section{GEREÇ VE YÖNTEM}

\section{Araştırmanın tipi:}

Bu çalışma, yarı deneysel tasarımına sahip olup, tek araştırma grubu kullanılmıştır.

\section{Evren ve Örneklem:}

Araştırmada Düzce illinde Aile ve Sosyal Politikalar Müdürlüğü'ne bağlı ve toplam 111 yaşlı bireyin bulunduğu tek kurum olan bir huzurevi seçilmiştir. Bu yaşılıarın yaklaşık olarak yarısı rehabilitasyon bölümündedir. Araştırmaya alınma kriterlerine uyan 16 yaşlı birey çalışma kapsamına alınmıştır. 
Çalışmaya alınma kriterleri;

- Hafif düzeyde demansı olmak,

- Illetişime açık olmak,

- Sanat terapisi etkinliklerine katılmaya istekli olmak.

\section{Veri Toplama Araçları:}

Çalışmanın verileri, araştırmacılar tarafından hazırlanan "Bireysel Bilgi Formu" ve "Standardize Mini Mental Test" (MMT) kullanılarak toplanmıştır. Mini Mental Test Güngen ve arkadaşları (15) tarafından hafif demans hastalarında geçerlilik-güvenilirliği yapılmış, puan aralığı 0-30 arasında değişen, eşik değeri 23/24 olan bir ölçüm aracıdır. Yönelim, kayıt-hafıza, dikkat-hesap, hatırlama, lisan yeteneklerini test eder. Veri toplama formları hastalarla yapılan yüz yüze görüşmeler ile yaklaşık olarak 20-35 dakikalık bir sürede toplanmıştır. Çalışmada sanat terapisi ile duygusal uyaran verilme yönteminin bilişsel durum üzerine etkisi girişim öncesi, girişimden üç ay sonra yapılan ölçümlerde Mullanılarak değerlendirilmiştir.

\section{Sanat Terapisi Etkinlikleri:}

Çalışmada, araştırmacılar içinde yer alan üniversitede grafik tasarımı bölümü öğretim görevlisi tarafından resim, heykel, nesne-canlı resmi boyama, kolaj vb. teknikler kullanılarak "Sanat Terapisi" uygulanmıştır. Çalışmada uygulamalar için kurumda hobi odası olarak düzenlenen bir oda kullanılmıs olup sanatsal çalışmalar 24.02.2014-12.05.2014 tarihleri arasında her hafta bir tam gün olacak şekilde yürütülmüştür.

\section{Verilerin değerlendirilmesi:}

Çalışmadan elde edilen veriler kodlanarak bilgisayar ortamına aktarıldıktan sonra bir istatistik programıyla değerlendirilmiştir. Sürekli değişkenler ortalamaıstandart sapma veya ortanca [çeyreklikler arası genişlik]; kategorik değişkenler sayı ve yüzde ile gösterilmiştir. Örneklem grubunun öntest ve sontest puanları arasında bir fark olup olmadığını belirlemek amacıyla parametrik olmayan Wilcoxon-işaretli-sıralama testi kullanılmıştır. İstatistiksel anlamlılık için güven aralığı $<0,05$ olarak belirlenmiştir.

\section{Etik Konular:}

Araştırmanın yapılabilmesi için araştırmanın yapılacağı kurumdan resmi, katılımcılardan sözlü onam alınmıştır.

\section{BULGULAR}

Yaş ortalaması $73,0 \pm 7.70$ olan yaşlıların, \%62.5'i kadın, \%50'si bekâr ve \%68,8'inin çocuğu vardır. \%43,8'i okur-yazar olup, sadece $\% 12,5$ 'si ilköğretim mezunudur ve eğitim görenlerin toplam eğitim süreleri ise $3,33 \pm 2,12$ yıldır. Yaşlıların \%75'i erişkinlik döneminde aktif olarak çalışma hayatında yer almışlardır. Çalışan yaşııların çalışma yılı ortalaması $18,5 \pm 13,29$ yıldır. Ortalama huzur evinde kalış süreleri $28,63 \pm 20,18$ ay olan yaşlıların $\% 56,3$ 'ünün sosyal güvencesi bulunmaktadır (Tablo 1).

Yaşlıların sağlık durumları kendilerine sorulduğunda; \%11'i bir ya da daha fazla sağlık sorunu olduğunu ve en çok eklem-kas ağrısı $(\% 37,5)$, diyabet $(\% 37,5)$ ve hipertansiyon $(\% 18,8)$ hastalıklarının olduğunu bildirmiştir. Mevcut kronik hastalıkları doğrultusunda $\% 68,8^{\prime}$ inin düzenli ilaç kullandığı ve en çok alınan ilaçların antidiyabetik (\%37,5), analjezik $(\% 41,7)$ ve antihipertansif ilaçlar $(\% 18,8)$ olduğu belirlenmiştir. (Tablo 2).

Yaşlıların \%81,3'ü kurum içerisinde boş vakitlerini değerlendirdiklerini bildirmiştir. Boş vakitlerini değerlendirmede yaptıkları aktiviteler arasında spor yapma $(\% 37,5)$, el işi yapma (\%25), kitap okuma (\%12,5), müzik dinleme $(\%$ 18,8), ibadet etme $(\% 12,5)$, 
bulmaca çözme $(\% 6,3)$, televizyon izleme $(\% 12,5)$ ve boyama yapma $(\% 12,5)$ yer almaktadır. Sağ ve sol el kullanımı açısından yaşılıarın tamamı aktif olarak sağ ellerini kullanmaktadırlar.

Tablo 1. Yaşılıarın Sosyo-Demografik Özelliklerinin Dağılımı $(n=16)$

\begin{tabular}{|c|c|c|c|}
\hline \multicolumn{2}{|c|}{ Sosyo-Demografik Özellikler } & \multirow{2}{*}{$\begin{array}{l}\mathbf{n} \\
10\end{array}$} & \multirow{2}{*}{$\begin{array}{c}\% \\
62,5\end{array}$} \\
\hline \multirow{2}{*}{ Cinsiyet } & Kadın & & \\
\hline & Erkek & 6 & 37,5 \\
\hline \multirow[t]{2}{*}{ Yaş (OrtıSS yıl) } & $73,0 \pm 7,70$ & \multicolumn{2}{|c|}{ (Min-Max: $60-88$ ) } \\
\hline & Bekar & 8 & 50 \\
\hline \multirow[t]{2}{*}{ Medeni Durum } & Evli & 1 & 6,3 \\
\hline & Dul & 7 & 43,8 \\
\hline \multirow[t]{3}{*}{ Çocuk Durumu } & Var & 11 & 68,8 \\
\hline & Yok & 5 & 31,3 \\
\hline & Okur-yazar değil & 7 & 43,8 \\
\hline \multirow[t]{2}{*}{ Eğitim Durumu } & Okur-yazar & 7 & 43,8 \\
\hline & İlköğretim mezunu & 2 & 12,5 \\
\hline $\begin{array}{l}\text { Eğitim } \\
\text { Süresi(Ort } \pm S S \text { yıl) }\end{array}$ & $3,33 \pm 2,12 Y_{I} l$ & \multicolumn{2}{|c|}{ (Min-Max: 1-8) } \\
\hline \multirow{2}{*}{ Aktif Çalışma } & Evet & 12 & 75,0 \\
\hline & Hayır & 4 & 25,0 \\
\hline $\begin{array}{l}\text { Çalışma } \\
\text { Süresi(OrtıSS yıl) }\end{array}$ & $18,5 \pm 13,29$ & \multicolumn{2}{|c|}{ (Min-Max: 5 - 43) } \\
\hline $\begin{array}{l}\text { Huzurevinde Kalma } \\
\text { Süresi (Ort } \pm S S \text { ay) }\end{array}$ & $28,63 \pm 20,18$ & \multicolumn{2}{|c|}{ (Min-Max: $5-72$ ) } \\
\hline \multirow{2}{*}{ Sosyal Güvence } & Var & 9 & 56,3 \\
\hline & Yok & 5 & 43,8 \\
\hline
\end{tabular}

Örneklem grubunun ön test ve sanat terapi sonrası son testten aldıkları yönelim, kayıthafıza, dikkat-hesap, hatırlama, lisan yetenek alanı puanları ve MMT toplam puan ortalamaları Tablo 3'de verilmiştir. Grubun ön test MMT puan ortalaması 20,63 olup standart sapması 3,40'dır. Grubun son test MMT puan ortalaması ise 19,75 standart sapması 4,86'dır. Yaşlıların yönelim, kayıt-hafıza, hatırlama, lisan yetenek alanı ve MMT toplam son test puan ortalamalarında düşüş olduğu, dikkat-hesap yetenek alanından aldıkları son test puan ortalamalarında ise bir artış olduğu belirlendi (Tablo 3).
Yaşlıların ön test-son test MMT puanları arasındaki farkı test etmek amacıyla yapılan Wilcoxon işaretli sıralama testi sonuçları Tablo 4'de verilmiştir. Test sonuçlarına göre sadece MMT yönelim yetenek alanında son test puan ortancasının ön test puan ortancasına göre daha düşük olduğu, diğer MMT yetenek alanları ve toplam MMT puan ortancalarında herhangi bir değişimin olmadığı görüldü ve sonuçta ön test-son test puanlarında istatistiksel açıdan anlamlı bir farkın olmadığı sonucuna varılmıştır $(p>0,05)$.

Tablo 2. Yaşııların Sağıık Sorunları ve Kullandığı İlaçların Dağılımı (n=16)

\begin{tabular}{|c|c|c|c|}
\hline \multicolumn{2}{|c|}{ Sağlık Sorunları ve Kullanılan illaçlar } & \multirow{2}{*}{$\frac{\mathbf{n}}{11}$} & \multirow{2}{*}{$\begin{array}{c}\% \\
68,8\end{array}$} \\
\hline Sağlık Sorununun Olması & Evet & & \\
\hline 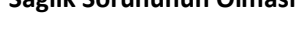 & Hayır & 5 & 31,3 \\
\hline \multirow{2}{*}{ Diyabet } & Evet & 4 & 25,0 \\
\hline & Hayır & 12 & 75,0 \\
\hline \multirow{2}{*}{ Hipertansiyon } & Evet & 3 & 18,8 \\
\hline & Hayır & 13 & 81,3 \\
\hline \multirow{2}{*}{ Eklem ve Kas Ağrısı } & Evet & 6 & 37,5 \\
\hline & Hayır & 10 & 62,5 \\
\hline \multirow{2}{*}{ Uyku Sorunu } & Evet & 1 & 6,3 \\
\hline & Hayır & 15 & 93,8 \\
\hline \multirow{2}{*}{ Solunum Problemleri } & Evet & 1 & 6,3 \\
\hline & Hayır & 15 & 93,8 \\
\hline \multirow{2}{*}{ Düzenli İlaç Kullanımı } & Evet & 11 & 68,8 \\
\hline & Hayır & 5 & 31,3 \\
\hline \multirow{2}{*}{ Antihipertansif ìlaçlar } & Evet & 3 & 18,8 \\
\hline & Hayır & 13 & 81,3 \\
\hline \multirow{2}{*}{ Antidiyabetik İlaçlar } & Evet & 6 & 37,5 \\
\hline & Hayır & 10 & 62,5 \\
\hline \multirow{2}{*}{ Analjezik ìlaçlar } & Evet & 5 & 41,7 \\
\hline & Hayır & 7 & 58,3 \\
\hline \multirow{2}{*}{ Uyku ìlacı } & Evet & 1 & 6,3 \\
\hline & Hayır & 15 & 93,8 \\
\hline \multirow{2}{*}{ КОАН İlacı } & Evet & 1 & 6,3 \\
\hline & Hayır & 15 & 93,8 \\
\hline
\end{tabular}

\section{TARTIŞMA}

Bu çalışmanın genel amacı demanslı hasta bakımının temel niteliklerinden biri olan yaşam kalitesini sürdürecek terapötik ortamın sağlanmasıdır (2). Bu doğrultuda sanat terapisi, günlük bakım/yatılı bakım 
ortamındaki demanslı yaşlıların duygu durum ve bilişsel özellikleri üzerinde olumlu etkilere sahip olduğu ile ilgili sonuçların ağırlıklı olarak ortaya konulduğu psikoterapötik bir tekniktir. Buradan yola çıkılarak bu çalışma bir huzurevinde hafif demans hastalarına yönelik yürütülen sanat terapisinin bilişsel durumları üzerindeki etkisinin değerlendirilmesi amacıyla 16 yaşlı bireyde gerçekleştirilmiştir. Sanat terapisinde kullanılan pek çok yöntem olmakla birlikte bu çalışmada resimsel sanat terapisi tercih edilmiştir. Nitekim resimsel sanat terapisinin psikopatolojik durumlarda kullanımının daha yaygın olduğu belirtilmektedir (7).

Tablo 3. Yaşlıların Ön test-Son test MMT Puanları

\begin{tabular}{lcc}
\hline \hline $\begin{array}{l}\text { MMT Yetenek } \\
\text { Alanları }\end{array}$ & MMT Öntest* & MMTSontest* \\
\hline Yönelim & $8,06 \pm 2,14$ & $7,38 \pm 2,03$ \\
Kayıt-hafıza & $2,88 \pm 0,34$ & $2,69 \pm 0,60$ \\
Dikkat-hesap & $0,25 \pm 0,58$ & $0,63 \pm 1,36$ \\
Hatırlama & $2,06 \pm 1,06$ & $1,81 \pm 1,11$ \\
Lisan & $7,38 \pm 0,96$ & $7,25 \pm 1,44$ \\
MMT Toplam & $20,63 \pm 3,40$ & $19,75 \pm 4,86$ \\
\hline \hline *Ortalama &
\end{tabular}

Çalışmanın yapıldığı kurumda bulunan yaşlılar içinde çalışmaya alınma kriterlerini karşılayan yaşlı sayısının yetersizliği nedeniyle çalışma sadece 16 yaşlı birey ile yürütülmüştür. Bunun en önemli nedeni huzurevindeki yaşlı profilinin, çoğunlukla ağır demans durumunda yaşılıardan oluşması ve yaşılıarın çalışmaya katılma konusundaki istekliliklerinin az olmasıdır. Diğer taraftan çalışmaya katılan yaşlıların büyük çoğunluğu (\%81) kurum içerisinde boş vakitlerini değerlendirdiklerini belirtmişlerdir. Bu aktiviteler arasında ise sanatsal etkinlik olarak kabul dilebilecek müzik dinleme (\%18), boyama yapma (\%13) da yer almaktadır. Ancak bu etkinlikler yaşlıların kendi kendilerine organize ettikleri ve herhangi bir danışman tarafından düzenli olarak sürdürülmeyen aktivitelerdir.

Tablo 4. Yaşlıların Öntest-Sontest MMT Puanlarının Karşılaştırılması

\begin{tabular}{lccc}
\hline \multicolumn{1}{c}{ Örneklem Grubu } & $\begin{array}{c}\text { Ortanca[Çeyreklikler } \\
\text { arası genişlik] }\end{array}$ & $\mathbf{z}$ & $\mathbf{p}$ \\
\hline Yönelim Ön test & $8,50[2,75]$ & - & \\
Yönelim Son test & $8,00[4,0]$ & 1,933 & 0,05 \\
Kayıt-hafıza Ön test & $3,00[0,0]$ & -1732 & 0,08 \\
Kayıt-hafıza Son test & $3,00[0,75]$ & & \\
& & & \\
Dikkat-hesap Ön test & $0,00[0,0]$ & - & 0,18 \\
Dikkat-hesap Son test & $0,00[0,75]$ & 1,342 & 0,18 \\
& & & \\
Hatırlama Ön test & $2,00[1,75]$ & - & 0,38 \\
Hatırlama Son test & $2,00[2,00]$ & 0,877 & 0,38 \\
& & & \\
Lisan Ön test & $7,00[1,00]$ & - & 0,82 \\
Lisan Son test & $7,00[2,75]$ & 0,229 & 0,82 \\
& & & \\
MMT Ön test & $21,50[4,75]$ & - & \\
MMT Son test & $21,50[8,75]$ & 0,949 & 0,34 \\
\hline \hline
\end{tabular}

Ayrıca yaşlıların yaşlıı ile ilgili algılamalarının olumsuz olmasının da çalışmaya katıım konusundaki istekliliği olumsuz bir şekilde etkilemiş olabileceği düşünülmüştür. Bazı yaşıllar "Yaşılıı deyince aklınıza ilk ne geliyor?" sorusuna verdikleri cevaplar ile olumsuz duygularını şu şekilde ifade etmiştir. "Yaşlılık ömrümü bitirdi, dünyadan hiç umudum yok" (MA, Kadın, 74 yaşında), "Yaşlılık buruk bir acı, aynı kivi gibi" (HY, Kadın, 68 yaşında), "Yaşlılık deyince aklıma ilk ölüm geliyor" (IA, Erkek, 88 yaşında), "Halsizlik, yorgunluk, çok yorgunum bir şey yapacak gücüm yok" (SE, Kadın, 81 yaşında), "Yaşlılık deyince aklıma ilk gençlik geliyor, keşke genç olabilseydim"(HM, Erkek, 77 yaşında).

Yaşlıların sanat terapisi etkinliği öncesi MMT puan ortalaması yaklaşık 21 puan, etkinlikten üç ay sonrası ise 20 puandır. Bu puanlar MMT için hafif demans referans aralığındadır ve etkinlik sonrasında anlamlı bir değişim olmamıştır. Yaşlıların MMT alt boyutları açısından yönelim, kayıt-hafıza, hatırlama, lisan puan ortalamalarında düşüş 
olduğu, dikkat-hesap yetenek alanından aldıkları son test puan ortalamalarında ise bir artış olduğu belirlenmiştir. Ancak bu değişimler açısından da anlamlı bir fark bulunmamıştır. Özdemir ve Akdemir (14) çalışmalarında çoklu uyaran yöntemi ile yürütülen sanat terapisinin yaşılıarın müdahale öncesi (19 puan) MMT puanlarına göre müdahale bittikten hemen sonra (28 puan) ve üç hafta sonrasında (27 puan) anlamlı olarak artmış olduğunu saptamıştır. Söz konusu çalışmada ölçümlerin yapıldığı süreler, sanat terapisinin etkinliğinin ölçümsel anlamda değerlendirilebileceği süreler açısından oldukça kısadır. Bu çalışmada en az kısa dönem sonuçlarını ortaya koymak adına üç ay sonra izlemsel ölçümler yapıımıştır. Yaşlıların üç ay sonraki MMT puanlarının değişmemiş olması hastalığın ilerleyici özelliği göz önünde bulundurularak makul bir sonuç olarak değerlendirilmiştir. Benzer şekilde Viola ve arkadaşları (16) orta düzey Alzheimer ve demans hastalarında sanat terapisini de içeren multidisipliner bilişsel rehabilitasyon programının etkinliğini değerlendirmiş (öncesi 23, sonrası 23) ve bilişsel özellikler bakımından deney grubunun sabit olduğunu, hafıza alt boyutunda anlamlıık sınırında bir azalma, dikkat alt boyutunda anlamlılık sınırında bir artış olduğunu belirlemişlerdir. Rusted ve arkadaşları (10) demanslı hastalarda sanat terapisinin etkinliğinin değerlendirildiği randomize kontrollü çalışmalarında bilişsel durum, hafıza ve dikkat üzerinde etkinlikten 1 ay ve 3 ay sonrasında anlamlı bir değişim olmadığını göstermişlerdir. Bu bulgulardan farklı bir şekilde Hattori ve arkadaşlarının (17) orta düzey Alzheimer hastalarında yaptıkları çalışmalarında sanat terapisinin bilişsel ve psikososyal etkileri kontrollü olarak incelenmiş etkinlik öncesi ve sonrası MMT sonuçlarında anlamlı bir artış olduğu belirlenmiştir.

\section{SONUÇ}

Sonuç olarak sanat terapisi demans hastalarında yaşam kalitesini yükseltmek için önerilen bir yöntemdir. Sanat terapisi yaşlı bireylerle küçük gruplar halinde düzenli olarak sürdürüldüğünde onların sosyalleşmeleri adına önemli bir kazançtır. Bu çalışmanın sınırlııkları, çalışma verilerinin çalışmaya katılan 16 yaşlı bireyi yansıtması, çalışmada tek grup üzerinden sanat terapisinin etkinliğinin değerlendirilmesi, sadece hafif düzeydeki demanslı yaşılıarın alınması ve test yöntemi olarak sadece nicel yöntemlerin kullanılmasıdır. Gelecekte sanat terapisinin Türkiye'de yaşayan yaşılıardaki sonuçlarını ortaya koyacak kontrollü ve uzun dönem izlemli çalışmalara gereksinim olduğu düşünülmektedir.

\section{KAYNAKLAR} 1. World Health Organization and Alzheimer's Disease
International. Dementia: A public health priority,
http://www.who.int/mental health/publications/dementiareport
2012/en/Accessed October 22, 2012.
2. Akyar I. Demanslı hasta bakımı ve bakım modelleri. Sağlık
Bilimleri Fakültesi Hemşirelik Dergisi 2007; 79-88.

3. McMaster M. Integrating nature into group art therapy interventions for clients with Dementia. Presented in Partial Fulfillment of the Requirements For the Degree of Master of Arts. Concordia University 2013, Montreal, Quebec, Canada.

4. Baines P. Quality demantia care: nurturing the hearth: creativity, art therapy and dementia. The Quality Dementia Care Series 2007; No: 3.

5. Chancellor B, Duncan A, Chatterjee A. Art therapy for Alzheimer's Disease and other dementias. Journal of Alzheimer's Disease 2014; 39:1-11.

6. Aydın B. Tıbbi sanat terapisi. Psikiyatride Güncel Yaklaşımlar 2012; 4 (1): 69-83.

7. Utaş Akhan L. Psikopatolojik sanat ve psikiyatrik tedavide sanatın kullanılışı. Yükseköğretim ve Bilim Dergisi 2012; 2(2): 132-135.

8. McFadden SH, Basting AD. Healthy aging persons and their brains: Promoting resilience through creative engagement.Clin GeriatrMed 2010; 26: 149-161.

9. Peisah C, Lawrence G, Reutens S. Creative solutions for severe dementia with BPSD: A case of art therapy used in an inpatient and residential care setting. Int Psychogeriatrics 2011; 23: 1011-1013.

10. Rusted J, Sheppard L, Waller D. A multicentre rondomized control group trial on the use of art therapy for older people with dementia. Group Analysis2006; 39 (4): 517-536.

11. Meguro $M$, Meguro K. Activated thalamic glucose metabolism after combined donepezil and psychosocial intervention. $\mathrm{Br} \mathrm{J}$ Neurosci Nurs 2010; 6: 176-180.

12. Safar LT, Press DZ. Art and the brain: Effects of dementia on art production in art therapy. Art Therapy 2011; 28: 96-103.

13. Mimica N, Kalinić D. Art therapy may be benefitial for reducing stress-related behaviours in people with dementia-case report. Psychiatr Danub 2011; 23 (1): 125-128.

14. Özdemir L, Akdemir N. Hafif Alzheimer hastalarına uygulanan çoklu duyusal uyaran yönteminin kognitif durum üzerine etkisi. Hacettepe Üniversitesi Hemşirelik Yüksekokulu Dergisi 2007; 1-11.

15. Güngen C, Ertan T, Eker E ve ark. Reliability and validity of the standardized Mini Mental State Examination in the diagnosis of mild dementia in Turkish population. Turk Psikiyatri Derg 2002;13:273-81.

16. Viola LF, Nunes PV, Yassuda MS et al. Effects of a multidisciplinar cognitive rehabilitation program for patients with mild Alzheimer's disease. Clinics 2011; 66 (8): 1395-1400.

17. Hattori $\mathrm{H}$, Hattori $\mathrm{C}$, Hokao $\mathrm{C}$ et al. Controlled study on the cognitive and psychological effect of coloring and drawing in mild Alzheimer's disease patients. Geriatr Gerontol Int 2011; 11: 431-437. 